\title{
Políticas Nacionais de Atenção Integral à Saúde de Adolescentes e Jovens e à Saúde do Homem: interlocuções políticas e masculinidade
}

\author{
Brazilian comprehensive health care policies for adolescents, \\ young men and the health of men: political debates and masculinity
}

Silvia Brãna Lopez ${ }^{1}$

Martha Cristina Nunes Moreira ${ }^{1}$

${ }^{1}$ Instituto Nacional de Saúde da Mulher, da Criança e do Adolescente Fernandes Figueira, Fundação Oswaldo Cruz. Av. Rui Barbosa 716, Flamengo. 22250-020 Rio de Janeiro RJ.

silvia.lopez@iff.fiocruz.br

\begin{abstract}
This paper analyzes the proposal of the Brazilian Comprehensive Health Care Policy for Adolescents and Young People-PNAISAJ, and the Brazilian Comprehensive Health Care Policy for Men - PNAISH, as policies that introduce a new way to address comprehensive health care for these population groups. From official documents, the debates among both policies were analyzed to identify: 1) how the relational perspective of gender and masculinity were considered in each policy; and 2) other key transversal concepts to the policies studied. While the category of life cycle marks the PNAISAJ proposal, the gender issue is paramount in the PNAISH proposal. We conclude that political texts express the interests and understanding of the field of knowledge of protagonists from each of the segments analyzed, constituting cultural policies with the power to establish some meanings for attention and care of health in different population groups.
\end{abstract}

Key words Public health policies, Adolescents, Young men and men, Masculinity, Gender, Cultural policies
Resumo Analisa-se a proposição da Política $\mathrm{Na}$ cional de Atenção Integral à Saúde de Adolescentes e Jovens - PNAISAJ e a Política Nacional de Atenção Integral à Saúde do Homem - PNAISH como instituidoras de uma nova compreensão para a atenção integral à saúde destas populações. A partir de documentos oficiais, analisaram-se as interlocuções entre a proposta da PNAISAJ e a da PNAISH para identificar: 1) como a perspectiva relacional de gênero e a masculinidade foram consideradas em cada política e 2) outros conceitoschaves transversais às politicas estudadas. Enquanto a categoria de ciclo de vida marca a proposta da PNAISAJ; na PNAISH, a marca do gênero é a que se destaca. Concluimos que textos politicos expressam os interesses e a compreensão do campo do conhecimento de atores de cada um dos segmentos analisados, constituindo políticas culturais com potência a instauração de certos sentidos à atenção e ao cuidado à saúde dos diferentes extratos populacionais.

Palavras-chave Políticas públicas, Adolescentes, homens jovens e homens, Gênero, Masculinidade, Politicas culturais 


\section{Introdução}

Os dados epidemiológicos relacionados aos índices de morbimortalidade da população de homens, obtidos ao longo da última década, segundo fontes do Datasus ${ }^{1}$, apresentam um cenário acerca da saúde dessa população que requer movimentos de aproximação e aprofundamento dos determinantes sociais e culturais que podem estar relacionados às causas da mortalidade e aos agravos. Dentre eles, destacamos aqueles associados às relações entre os gêneros e aos sentidos atribuídos à masculinidade, nos quais a adoção de comportamentos de risco e a negligência e/ou falta de informação sobre o autocuidado surgem como fatores que favorecem a elevação desses índices.

Estudos recentes ${ }^{2,3}$ apontam que alguns dos sentidos atribuídos à masculinidade hegemônica fortalecem a apropriação de representações que associam o masculino à força, à assertividade, à não-vulnerabilidade associada a uma crença de imunidade, à naturalização do descontrole sexual, à associação da sexualidade à penetração, dentre outras.

A ideia de invulnerabilidade pode ser tomada como um dos aspectos explicativos para uma menor procura por parte dos homens aos serviços de saúde preventivamente que, segundo estudo realizado por Gomes e Nascimento ${ }^{4}$, é influenciada pelas interdições de marcas identitárias relacionadas à masculinidade hegemônica, que quando vivenciadas e internalizadas pelo homem, cerceariam neste a busca por tais serviços. Isto porque tal procura seria a expressão de um sinal de fragilidade de sua masculinidade, de sua identidade de ser masculino. Com isso, o cuidar de si associado à procura de um serviço de saúde seriam naturalizados como mais próprios do feminino.

Ainda, segundo esse mesmo estudo, outros aspectos também podem concorrer para uma menor procura pelos homens aos serviços de saúde. Se, por um lado, a invulnerabilidade e a força relacionadas à masculinidade impedem que o homem demonstre sinais de fraqueza e medo, por outro, uma maior exposição do corpo a um profissional da área médica, seja ele homem ou mulher, ou o medo de encontrar algo que possa deflagrar um diagnóstico de doença são ideias relacionadas à possibilidade de se evidenciar uma fragilidade.

Os sentidos atribuídos à masculinidade que a associam à força e à imunidade também podem ser ligados a uma maior vulnerabilidade dos homens à mortalidade por causas externas e à mor- bidade por incapacitação, lesões, dentre outros agravos derivados das agressões não-fatais. Tais sentidos podem corroborar para uma maior exposição e enfrentamento a situações de risco e de violência vivenciadas por esta população.

Frente a este quadro, defendemos o aprofundamento da compreensão da influência, nos processos saúde-doença, das relações de gênero e dos modelos de masculinidade que são construídos socialmente e como esta compreensão pode contribuir para a (re)formulação das políticas públicas e ações estratégicas a elas associadas para a promoção da saúde da população brasileira.

Este artigo busca, com isso, explorar as interfaces entre a proposta, não promulgada, da Política Nacional de Atenção Integral à Saúde de Adolescentes e Jovens ${ }^{5}$ e a Política Nacional de Atenção Integral à Saúde do Homem ${ }^{6}$, já promulgada, tendo como categorias de ligação à perspectiva relacional de gênero e a masculinidade hegemônica e demais conceitos-chaves que perpassam ambos os textos políticos, com foco na saúde integral do homem ao longo da vida.

\section{Aporte conceitual e Metodologia}

Nossas análises se ancoraram numa perspectiva relacional de gênero, que compreende a construção social do que é ser masculino e do que é ser feminino num complexo de determinações e características culturais, familiares, grupais e individuais internalizadas ao longo da história de vida do sujeito ${ }^{7,8}$. A compreensão dos modelos de masculinidade e feminilidade, que prevalecem na sociedade nas relações gênero, potencializa as instâncias de governo em sua capacidade de produzir e implementar ações e programas no campo da saúde pública mais coadunados às formas do agir social produzido a partir das relações de gênero.

Acrescentamos a isto, as influências dos sentidos mais fortemente associados aos modelos de masculinidade e feminilidade que impõem desafios para o campo das políticas públicas de saúde, já que a masculinidade hegemônica, como o modelo de masculinidade que costuma emergir das relações hétero e homossexuais, define e orienta um certo agir sexual/social dos indivíduos; agir este que influencia o desenvolvimento de quadros mais ou menos graves nos índices de morbimortalidade e agravos na população de homens e, por justaposição, na de mulheres.

Tomado como um componente infectante ${ }^{9}$ no processo de adoecimento, o lugar do homem nos 
estudos no campo da saúde se apresenta mais voltado para a questão da doença do que da saúde, reafirmando que tal lógica - a da masculinidade hegemônica - também permeia a associação do homem ao seu lugar no campo da saúde.

Pautada na perspectiva relacional de gênero e no conceito de masculinidade hegemônica, foi realizada a leitura de textos do Ministério da Saúde, constituintes: 1) da proposta preliminar não promulgada da Política Nacional de Atenção Integral à Saúde de Adolescentes e Jovens - PNAISAJ ${ }^{10}$, resultado das oficinas e seminários realizados pela Área de Saúde do Adolescente e do Jovem do Ministério da Saúde ao longo do ano de 2005; 2) das Diretrizes Nacionais para a Atenção Integral à Saúde de Adolescentes e Jovens na Promoção, Proteção e Recuperação da Saúde ${ }^{5}$; 3 ) da Política Nacional de Atenção Integral à Saúde do Homem - PNAISH ${ }^{11}$; e 4) dos Princípios e Diretrizes da $\mathrm{PNAISH}^{6}$, a fim de construir um quadro associativo entre categorias analíticas identificadas como presentes em todos os textos políticos analisados, a saber: ano de publicação do texto político, tipo de publicação do texto político, elaboração prévia de princípio e diretrizes políticas, legislações citadas, estrutura de apresentação do texto político, atores participantes da construção do texto político e principais conceitos apresentados. Esta metodologia de análise toma por base a análise documental sugerida por Severino ${ }^{12}$.

Destacados os dados e os conceitos relacionados às categorias analíticas em cada texto político, foram identificados o contexto sócio-histórico da produção da política, os participantes de construção de cada texto político e principais conceitos identificados nos textos das políticas, analisando em que aspectos se aproximavam e em quais se distinguiam.

A partir da análise das relações entre tais elementos, foi possível a construção de uma análise argumentativa na qual buscamos explorar, na proposta da PNAISAJ e na PNAISH, a masculinidade numa perspectiva relacional de gênero como possibilidade de compreender os adolescentes/homens jovens e os homens como sujeitos com especificidades quanto ao cuidado no campo da promoção da saúde. Ao longo do processo de análise desses documentos, foram identificadas ainda bases teóricas e conceitos sobre os quais tais textos políticos se apóiam.

Cumpre destacar que, neste estudo, o texto foi compreendido de forma bastante ampliada ${ }^{13}$ e como expressão das produções sociais de sentidos acerca da saúde dos homens; produções essas engendradas pelos múltiplos atores da tes- situra social. Essas relações de forças sociais se realizam em um acervo de documentos oficiais, dentre os quais aqueles elegidos para a nossa análise: a proposta não promulgada de uma política nacional para adolescentes e jovens e a já institucionalizada Política Nacional de Atenção Integral à Saúde do Homem, além dos demais textos políticos que as embasam e compõem.

\section{Políticas públicas para a saúde integral da população masculina: conversando com as diferenças}

A saúde integral da população adolescente do binômio "crise-adolescência" ao binômio "protagonismo-jovem"

A pauta da atenção integral à saúde de adolescentes e jovens resulta de um complexo de influências que desencadeiam um processo de reconhecimento extrato populacional brasileiro algo em torno de 30 a $33 \%$ da população total ao longo da primeira década do século XXI, segundo fontes do IBGE - e emerge de um contexto global e local de amplo debate sobre os direitos humanos.

No âmbito global, este movimento foi disparado com a adoção das prerrogativas defendidas pela Convenção sobre os Direitos da Criança, adotadas a partir dos consensos das discussões promovidas na Assembleia Geral das Nações Unidades em 1989. Nesta, a adolescência é oficializada como programa a ser adotado pelas nações signatárias. Neste mesmo ano, o Ministério da Saúde brasileiro institui o Programa de Saúde do Adolescente - PROSAD, voltado para a população na faixa etária de 10 a 19 anos.

No âmbito local, cumpre ressaltar o contexto fortemente favorecedor das transformações jurídico-políticas voltadas para este grupo populacional: a Constituição Brasileira de $1988^{14}$, conhecida como a Constituição Cidadã, e o Estatuto da Criança e do Adolescente - ECA, em 1990 (Lei Federal no 8069 de 13 de julho de 1990) ${ }^{15}$ e, setorialmente, no campo da Saúde Pública, as Leis Orgânicas da Saúde de 1990 (Leis Federais no 8.080 de 19 de setembro ${ }^{16}$ e no 8.142 de 28 de dezembro $^{17}$, ambas de 1990). Tais instrumentos reinserem e legitimam um novo paradigma e compreensão do lugar conferido ao adolescente e ao jovem na sociedade, em que passam a ser considerados como sujeitos sociais para além da subordinação ao pátrio poder, à família e ao Estado.

A proposta não promulgada da Política $\mathrm{Na}$ cional de Atenção Integral à Saúde de Adolescentes e Jovens - PNAISAJ emerge, assim, de um 
cenário global de consolidação e defesa do estatuto de sujeito social conferido ao adolescente e ao jovem numa perspectiva de ciclo de vida. $\mathrm{Ou}$ seja, numa cuja centralidade se apoia numa etapa de vida de transição da infância para a vida adulta, complexa em relação às vivências experienciadas e ambíguas quanto às demandas sociais relacionadas a esta população. Essa ambiguidade ora destitui os adolescentes e jovens de uma plena autonomia decisória e de responsabilização, ora exige sua inserção no mundo produtivo, na participação das decisões de Estado, movimentos em defesa da cidadania, dentre outras.

Antes disto, no Brasil, o Código de Menores, em vigor no período de 1927 a 1990, estabelecia que os adolescentes e jovens poderiam ser acolhidos pelas políticas públicas pelas portas da assistência da forma ditada pelo Poder Público em caso de abandono, pobreza, doença e/ou infração; condições estas em que o Estado estaria legitimado a intervir e tutelar aqueles demandantes de tratamento e inaptos à compreensão e à reivindicação de suas próprias necessidades; passíveis, com isso, de serem encaminhados a instituições voltadas ao seu tratamento e/ou a sua ressocialização.

$\mathrm{Na}$ esfera jurídica do Estado, se operavam os processos de destituição do poder dos pais e da família na figura dos Juízes de Menor que, contavam com dispositivos auxiliares e aparatos subsidiários à materialização e à operacionalização da assistência estatal por intermédio de profissionais de outras esferas disciplinares (médicos, assistentes sociais, agentes educacionais, dentre outros) legitimados nos chamados "complexos tutelares"18.

A PNAISAJ, em sua proposta preliminar de 2007, inaugura um esforço por um espaço mais ampliado de participação e debate sobre a saúde da população jovem. No Brasil, esta perspectiva foi localmente apropriada, reconstruída e expressa numa proposição de uma política nacional de atenção integral, com vista à universalização das ações a esta política relacionadas, para além de uma perspectiva programática e pontual a certos segmentos populacionais com este perfil, incluindo a participação não só de entidades, profissionais e estudiosos do campo da adolescência e da juventude, mas também de grupos organizados de adolescentes e jovens numa perspectiva de incentivo ao protagonismo juvenil ${ }^{19,20}$ na identificação de suas necessidades específicas e na definição de suas prioridades dentro das competências da esfera da saúde pública.

Do binômio "crise-adolescência" em direção ao binômio "protagonismo-jovem" - esta traje- tória se apresenta como o aspecto mais inovador desta proposição política, marcada em seu texto por uma ampliação da concepção da adolescência e juventude atravessada por traços de múltiplas compreensões sobre o que é ser adolescente e jovem.

\section{A saúde integral da população masculina adulta: da "invisibilidade do poder" ao "poder da visibilidade"}

Identificamos a inexistência de uma política específica voltada para os homens adultos por um longo período de tempo tanto na esfera local, como na global. A proposta de instituir a Política Nacional de Atenção Integral à Saúde do Homem - PNAISH tem uma historicidade muito anterior a da Portaria Ministerial que a instituiu em agosto de 2009. O fato da sua institucionalização ser recente expressa algo para além de uma negligência em relação a este extrato populacional, mas uma série de valores que reforçam quase que a não necessidade do homem cuidar de sua saúde ou ser olhado por esta perspectiva.

A construção de uma política voltada para a saúde integral dos homens tem como marco histórico o discurso de posse do Ministro José Temporão, em 19 de março de 2007, que afirma como um de seus compromissos de governo "instituir a Política Nacional de Atenção Integral à Saúde do Homem (Compromisso no 10)"21. Tal compromisso não se constituiu como uma construção resultante de demandas reivindicatórias de movimentos sociais dos homens e não nos remete de forma imediata a uma necessidade de atendimento diferenciado e específico em relação à população masculina no Brasil, uma vez que esta não é reconhecida como excluída ou prescindida socialmente.

Por hipótese, o homem, por ocupar mais frequentemente espaços de poder e liderança, até então não fora reconhecido em suas especificidades. O lugar do poder masculino na sociedade, ao mesmo tempo que o insere numa posição privilegiada na hierarquia social, o exclui do reconhecimento de suas diferenças. É como se o masculino se constituísse num poder normatizado e diluído, indiferenciado no corpo social e acima de qualquer vulnerabilidade à sua saúde. É a partir do homem, socialmente colocado como norma, que se reconhece a diferença do(s) outro(s) e, a partir dele, se estabelecem os referenciais para o debate em relação a programas específicos a outros segmentos da população.

A partir da PNAISH, a população de homens adultos, com o reconhecimento de sua singulari- 
dade, é deslocado no âmbito do SUS de uma invisibilidade daquele que não era identificado como uma parcela da população que, mesmo significativa, não demandava serviços espacial e profissionalmente diferenciados de atendimento. $\mathrm{O}$ homem era tratado pelo sistema somente quando agravos de mais difícil e dispendioso controle já estavam instalados: a doença suplanta a saúde num cenário negligenciado quanto à atenção básica da população masculina. A PNAISH propõe, em seu projeto político, que o ingresso do homem aos serviços de saúde se dê pela perspectiva do cuidado, como um descaminho ao desfecho do adoecimento. Da "invisibilidade do poder" conferido ao homem, o projeto político da PNAISH expressa um esforço para "o poder da visibilidade" do cuidado requerido por esta população, até então não acolhido pelo SUS em suas especificidades.

Pode-se observar, portanto, nesse período, que as duas políticas - PNAISH e a proposta preliminar de uma PNAISAJ - se comunicam pela ideia de prevenção e promoção à saúde com foco na Atenção Básica, como estratégia de minorar as demandas de média e alta complexidade do SUS.

\section{Interlocuções políticas: gênero e ciclo de vida como delimitadores das políticas}

No Quadro 1, as duas políticas analisadas foram organizadas em eixos que demarcam objetivamente sua institucionalidade e os atores que participaram de suas elaborações.

Numa perspectiva de análise do contexto histórico, a proposta preliminar da Política Nacional de Atenção Integral à Saúde de Adolescentes e Jovens - PNAISAJ se constitui numa revisão e ampliação de políticas já anteriormente engendradas no âmbito do Sistema de Atenção à Saúde a este segmento populacional, como o Programa de Saúde do Adolescente - PROSAD no final da década de 80. Inaugura, assim, uma nova compreensão sobre o papel dos adolescentes e jovens em sua inserção social e institui uma política de governo mais estável e permanente para esta população, para além do caráter programático e, portanto, mais suscetível à descontinuidade, da política anteriormente estabelecida.

Primeiramente, amplia o limite superior da faixa etária da população a ser contemplada pelas suas ações programáticas, anteriormente definidas como dos 10 aos 19 anos, sendo agora proposta para o grupo etário dos 10 aos 24 anos. Com isso, uma parcela da população fora da faixa etária considerada como pertinente à ado- lescência - a qual se encerra aos 19 anos - é compreendida em uma transitoriedade da adolescência para a vida adulta num continuum vivenciado como juventude.

Em segundo lugar, propõe outra perspectiva da adolescência não como uma etapa crítica, uma etapa problema do ciclo de vida do indivíduo, mas uma perspectiva dos adolescentes e jovens como sujeitos de direito, construtores de suas próprias histórias de vida, participantes e corresponsáveis pelos processos sociais dos quais tomam parte.

Em terceiro lugar, propõe uma mudança de perspectiva da atenção à saúde desta população de um olhar sobre a doença e seus agravos para a atenção básica como estratégia política de promoção da saúde a esse segmento populacional, haja vista o grau de resolutividade deste nível de atenção na população jovem. Por fim, considera a perspectiva relacional de gênero como um fator que participa dos condicionantes sociais de saúde-doença para este segmento expressivo da população.

Tanto a proposta preliminar da proposição de uma PNAISAJ, quanto o texto das Diretrizes Nacionais para a Atenção Integral à Saúde de Adolescentes e Jovens na Promoção, Proteção e Recuperação da Saúde, submetido e aprovado pela Comissão Tripartite em novembro de 2009, instituem como eixos estratégicos comuns para a saúde integral da população de adolescentes e jovens: (a) o acompanhamento do crescimento e desenvolvimento saudáveis, onde se declaram as preocupações em assegurar as condições ambientais e individuais que favoreçam o pleno desenvolvimento e crescimento do adolescente e jovem, conforme seu repertório biológico, e (b) o foco na saúde sexual e saúde reprodutiva, ao atuar da prevenção e na intervenção precoce junto aos adolescentes e jovens em situação de vulnerabilidade e risco, favorecendo a promoção da saúde e a prevenção de doenças e agravos na idade adulta, com o incentivo à equidade de gênero e ao cuidado de si entre os adolescentes e homens jovens.

O texto da proposta política, distintamente do das Diretrizes Nacionais, enuncia como um terceiro eixo estratégico, a redução da mortalidade por causas externas desse extrato populacional; já nas diretrizes, o eixo estratégico confere centralidade à atenção integral no uso abusivo de álcool e outras drogas por pessoas jovens.

No que se refere à relação entre os textos das propostas políticas - PNAISAJ e PNAISH - e suas respectivas diretrizes, uma inversão da diretiva enunciada nas Diretrizes Nacionais para a Aten- 
Quadro 1. Quadro associativo entre as Políticas Nacionais de Atenção Integral orientadas por Ciclo de Vida/Gênero.

\begin{tabular}{|c|c|c|}
\hline & $\begin{array}{l}\text { PNAISH:Política Nacional de } \\
\text { Atenção Integral à Saúde do } \\
\text { Homem }\end{array}$ & $\begin{array}{c}\text { Proposta de uma PNAISAJ:Proposta de uma } \\
\text { Política Nacional de Atenção Integral à Saúde } \\
\text { de Adolescentes e Jovens }\end{array}$ \\
\hline Ano de publicação & 2009 & Proposta preliminar de 2007. \\
\hline $\begin{array}{l}\text { Forma de } \\
\text { publicação }\end{array}$ & $\begin{array}{l}\text { Portaria Ministerial no } 1.944 \\
\text { de } 27 / 08 / 2009 \text { e Publicação. } \\
\text { Cadernos da série B da SAS/ } \\
\text { DAPE/MS. }\end{array}$ & $\begin{array}{l}\text { Texto final da política não promulgado, sendo } \\
\text { o texto de acesso restrito e ainda não } \\
\text { publicado. }\end{array}$ \\
\hline $\begin{array}{l}\text { Presença de } \\
\text { Princípios e } \\
\text { Diretrizes }\end{array}$ & $\begin{array}{l}\text { Dupla referência: a) Presente } \\
\text { parcialmente no corpo da } \\
\text { Portaria Ministerial e b) } \\
\text { Presente integralmente de } \\
\text { forma dissociada ao texto da } \\
\text { Portaria, conferindo a esta seus } \\
\text { aspectos argumentativos. }\end{array}$ & $\begin{array}{l}\text { Presente integralmente. Dissociado do texto } \\
\text { político, tomando-o por base. As Diretrizes } \\
\text { Nacionais para a Atenção Integral à Saúde de } \\
\text { Adolescentes e Jovens na Promoção, Proteção } \\
\text { e Recuperação da Saúde foram submetidas e } \\
\text { aprovadas pela Comissão Tripartite em } \\
\text { dezembro de 2009, sendo publicadas em 2010, } \\
\text { como Normas e Manuais Técnicos, Série A da } \\
\text { SAS/DAPE/MS. Direcionado para gestores e } \\
\text { profissionais de saúde, reduzindo à proposição } \\
\text { política a diretivas voltadas a determinados } \\
\text { setores da área da saúde. }\end{array}$ \\
\hline $\begin{array}{l}\text { Legislações citadas } \\
\text { nos textos }\end{array}$ & $\begin{array}{l}\text { CF de 1998, Lei no } 9503 \text { de } \\
\text { 1998, Portaria GM/MS no } 325 \text {, } \\
\text { de } 21 \text { de fevereiro de } 2008 \text {. }\end{array}$ & $\begin{array}{l}\text { CF de } 1988 \text {; PROSAD de } 1989 \text {, Lei no } 8.069 \\
\text { de } 13 / 07 / 90 \text { (ECA), Lei Orgânica da Saúde no } \\
8.080 \text { de } 19 / 09 / 90 \text {, Lei no } 8.142 \text { de } 28 / 12 / 90 \text {, } \\
\text { Lei no } 8.742 \text { de } 07 / 12 / 93 \text {, Lei Federal no } 9.263 \\
\text { de } 12 / 01 / 1996 \text {, Portaria } n^{\circ} 648 / \text { GM de } 28 / 03 \text { / } \\
2006 \text { e Lei no } 11.343 \text { de } 23 / 08 / 2006 \text {. }\end{array}$ \\
\hline $\begin{array}{l}\text { Estrutura do texto } \\
\text { político }\end{array}$ & $\begin{array}{l}\text { Artigos no corpo da Portaria e } \\
\text { em Capítulos e Seções no } \\
\text { documento que integra os } \\
\text { Princípios e Diretrizes. }\end{array}$ & $\begin{array}{l}\text { Em Capítulos e Seções, tanto na versão } \\
\text { preliminar da proposição política, quanto no } \\
\text { texto das Diretrizes Nacionais. }\end{array}$ \\
\hline $\begin{array}{l}\text { Atores } \\
\text { participantes da } \\
\text { construção do } \\
\text { texto político }\end{array}$ & $\begin{array}{l}\text { Sociedades Médicas, } \\
\text { profissionais da saúde, } \\
\text { pesquisadores, acadêmicos, } \\
\text { representantes do CONASS e } \\
\text { CONASEMS e entidades civis } \\
\text { organizadas. }\end{array}$ & $\begin{array}{l}\text { Coordenadores estaduais e municipais } \\
\text { responsáveis pela saúde de adolescentes e } \\
\text { jovens, profissionais de saúde, acadêmicos, } \\
\text { conselhos profissionais, áreas de interface no } \\
\text { MS, entidades civis organizadas, grupos de } \\
\text { adolescentes e de jovens. }\end{array}$ \\
\hline $\begin{array}{l}\text { Principais } \\
\text { conceitos }\end{array}$ & $\begin{array}{l}\text { Saúde do Homem; } \\
\text { Integralidade; } \\
\text { Interssetorialidade; } \\
\text { Planejamento reprodutivo } \\
\text { masculino; Saúde da Família; } \\
\text { Protagonismo social; Enfoque } \\
\text { de Gênero; Masculinidades. }\end{array}$ & $\begin{array}{l}\text { Adolescente e jovens como sujeitos sociais de } \\
\text { direito (Doutrina da Proteção Integral); } \\
\text { Adolescências e Juventudes Plurais; População } \\
\text { Jovem; Protagonismo Juvenil; Enfoque de } \\
\text { Gênero; Desigualdade socioeconômica e racial; } \\
\text { Vulnerabilidade; Interssetorialidade; Promoção } \\
\text { da Saúde, Integralidade. }\end{array}$ \\
\hline
\end{tabular}


ção Integral à Saúde de Adolescentes e Jovens na Promoção, Proteção e Recuperação da Saúde pode ser observada quando comparada com as diretrizes associadas à Política Nacional de Atenção Integral à Saúde do Homem - PNAISH.

Isto porque a Portaria Ministerial no 1.944 de $27 / 08 / 2009^{11}$, que enuncia a PNAISH, toma por base as Diretrizes e Princípios da Política Nacional de Atenção Integral à Saúde do Homem que, por sua vez, se apresenta como uma discussão mais ampliada dos atores que participaram da construção da política, num esforço para a consolidação dos distintos olhares relacionados às prioridades e estratégias que deveriam ser nela focalizadas e fornecendo elementos argumentativos para a legitimação da política do homem.

As Diretrizes Nacionais para a Atenção Integral à Saúde de Adolescentes e Jovens na Promoção, Proteção e Recuperação da Saúde, num outro sentido, se (e)anuncia como um texto que toma por base a Política Nacional de Atenção Integral à Saúde de Adolescentes e Jovens e que pretende sensibilizar os gestores e os profissionais da saúde relacionados à saúde de adolescentes e jovens. Ao reconhecer os determinantes sociais nos processos de adoecimento e os limites do campo da saúde em seus esforços e ações voltadas à promoção, proteção e recuperação da saúde desta população, tais diretrizes se ancoram na ideia de que o pleno atendimento à saúde desta população implica uma demanda em rede da sociedade, posto que este grupo etário juridicamente remete a uma rede de adultos e às instituições por estes ocupadas, tais como: a família, a escola, o Estado, etc. Daí, observarmos a centralidade que a interssetorialidade assume neste texto político que ocupa integralmente o décimo capítulo da publicação - se constituindo numa estratégia política de ampliação dos limites de cada área de atuação política e potencialização de ações de forma coordenada entre diferentes áreas (saúde, educação, assistência social, etc.) e esferas de governo e participação social (município, estado, federação, terceiro setor e sociedade civil).

A Política Nacional de Atenção Integral à Saúde do Homem se caracteriza por seu ineditismo, uma vez que anteriormente a ela não existia nenhuma política focada na promoção e atenção integral deste extrato da população. A Portaria Ministerial que a institui declara não só a abrangência de suas ações pautadas nos princípios da universalidade, da equidade e da integralidade como seu foco político estratégico, mas propõe também o estabelecimento de diálogos com políticas que norteiam outras ações no âmbito do
SUS, tais como, a humanização, a corresponsabilização e a interssetorialidade, a educação em saúde e a participação da comunidade.

A partir disso, lista seis diretrizes a serem observadas na construção dos planos vinculados a tal política, a saber: foco na integralidade, na organização dos serviços para o acolhimento e a inclusão desta população, na hierarquização da implementação da política prioritariamente quanto à atenção básica e estrategicamente na Saúde da Família e na intersetorialidade. Enumera, a seguir, treze objetivos de múltiplo caráter, marcados pela diversidade e pela abrangência de escopo com metas a serem atingidas, muitas das quais relacionadas à prevenção de doenças e seus agravos. Define, ainda, as competências de cada esfera de governo - federal, estadual e municipal - na estruturação dos planos e ações relacionadas a esta política e enuncia, por fim, as instâncias sociais e de governo que integrarão o processo de avaliação da implementação da política.

Em nossa leitura, na seção destinada à declaração dos objetivos desta política é que reside a marca da ampla participação quando observada a pluralidade de atores que tomaram parte da construção do texto oficial da política, a saber, "Sociedades Médicas, profissionais da saúde, pesquisadores, acadêmicos, representantes do CONASS e CONASSEMS e de entidades civis

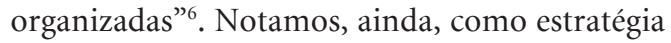
da PNAISH para o estabelecimento de uma comunicação entre as instâncias de divulgação e de governabilidade da política com os territórios associados ao masculino, a aproximação destas às associações civis, pensadas como territórios de convivência de homens, tais como clubes, associações desportivas, associações de trabalhadores e sindicatos e, por isso, identificados como espaços privilegiados de disseminação de uma nova perspectiva para a população masculina acerca do cuidado de si. São considerados ainda os espaços de privação da liberdade, como os presídios e as casas de detenção, onde, a vulnerabilidade e a violência por aqueles que em algum momento a promoveram, devem ser considerados em suas especificidades numa interlocução com as instâncias judiciais e de proteção social.

Temáticas centrais e recorrentes aos textos políticos analisados também podem ser observadas, como é o caso do destaque dado à violência como um fenômeno resultante de uma multiplicidade de fatores, interdependentes e de difícil identificação quanto às suas origens, o que limitaria as ações de atenção à saúde a uma atuação pontual e destacada do complexo do qual 
toma parte. Nesse sentido, os documentos expressam a importância das ações voltadas para a promoção da saúde como uma medida para a prevenção da violência e seus desdobramentos em termos de morbimortalidade e agravos na população masculina.

A delegação culturalmente construída das atribuições relacionadas ao cuidado a serem associadas exclusivamente como sendo de caráter feminino ${ }^{22,23}$ resulta, não raro, num "natural" distanciamento do progenitor na participação no cuidado e nos processos educacionais e de desenvolvimento emocional dos filhos, incrementando, com isso, comportamentos pouco comprometidos com uma paternidade responsável. O olhar sobre as relações sociais numa perspectiva de gênero impõe mudanças estratégicas na estruturação da abordagem do homem no Sistema de Saúde em favor da equidade entre os gêneros.

Identifica-se, portanto, a equidade entre os gêneros como um outro foco presente nestas construções políticas. No caso da proposta não promulgada da PNAISAJ, essa equidade se expressa na ênfase de uma perspectiva de cultura para a paz e de empoderamento do gênero feminino. Por sua vez, na PNAISH, a equidade entre os gêneros se expressa numa perspectiva familiar e afetivorelacional ao tratar das questões relacionadas à prevenção da violência nesses espaços.

Podemos identificar, também, outras temáticas estruturantes que perpassam de forma transversal as políticas analisadas: a equidade, a universalidade e a integralidade - princípios norteadores do SUS; a interssetorialidade - a importância de não se constituírem como políticas de ações isoladas ao reafirmarem a necessária interlocução com as demais esferas de ação política; o foco estratégico na promoção à saúde e o reconhecimento da heterogeneidade dos extratos populacionais a que se voltam.

Observamos, ainda, que as questões de gênero se apresentam de forma matizada e transversalmente em ambas as políticas: para a adolescência e juventude, a política parte da dimensão do ciclo de vida; enquanto que na voltada para o homem, o ciclo de vida se apresenta como um pano de fundo, sendo o foco deslocado para a questão do masculino.

Como trajetória de construção dos textos políticos, ambas se aproximam por adotarem uma inovadora metodologia para a construção de uma política pública a partir de um esforço para uma participação mais abrangente de múltiplos setores da sociedade. A estratégia da utilização do dispositivo de consulta pública aponta para a busca de valorização da participação da sociedade civil, intelectuais e governo no texto político. Nesse ponto, introduzimos o conceito de comunidades epistêmicas como um componente explicativo à emersão de lógicas distintas nas proposições políticas aqui analisadas, no sentido de que essas comunidades de especialistas se comunicam com temas da vida concreta e possibilitam a geração de um acúmulo cognitivo e crítico a partir de diversos conceitos. Haas (apud Farias ${ }^{24}$ ) compreende tais comunidades como "rede de profissionais com especialistas reconhecidos e competentes num domínio particular e com uma autoridade legitimada em termos de conhecimento politicamente relevantes associado àquele domínio ou área de conhecimento". Tais comunidades guardam forte relação entre a legitimação de saberes por ela emanados e as redes de poder que se constituem a partir da promoção de um regime de verdade legitimado por este saber.

Com isso, identifica-se que as políticas públicas voltadas para a atenção integral da saúde de adolescentes e jovens e da saúde do homem carreiam determinados sentidos ao só do que é adolescência, juventude e maturidade saudáveis e seu contraponto - doença, mas também acerca da masculinidade, valorizando certos sentidos e não outros por se constituírem como expressões de produções sociais.

\section{Conclusões}

Ampliar o debate sobre a saúde do homem no campo da saúde pública para além do paradigma biopsíquico significa refletir criticamente sobre toda uma agenda de ações e intervenções para o campo da saúde pública que reconheça as diferenças, com potência para se tornar cada vez mais inclusiva.

Como uma conclusão da análise dos documentos aqui proposta, considera-se que muitos sentidos sobre o homem e a masculinidade são postos. No entanto, os sentidos declarados como norteadores de determinadas estratégicas para a busca de caminhos que incentivem a entrada do homem jovem e do homem maduro no sistema pela atenção básica emergem de lógicas distintas. O primeiro se pauta numa busca por um protagonismo social mais ampliado e responsável e numa perspectiva de equidade de gênero; o segundo se apresenta mais fortemente marcado por uma lógica epidemiológica e clínica.

A distinção entre tais lógicas pode ser compreendida a partir de Carvalheiro ${ }^{25}$, uma vez que, 
ao compartilharem interesses no campo de conhecimento do qual participam e no qual são socialmente reconhecidos e valorizados, os atores sociais envolvidos tomam por base tal conhecimento para a produção de políticas. Os textos políticos expressam, portanto, a legitimidade e a valorização de saberes socialmente normatizados e produzidos por tais grupos. A metodologia utilizada para a construção dos textos políticos aqui analisados parte de um convite a diversos atores que, mesmo inseridos em lugares muito distintos socialmente, se reúnem em torno de um campo de conhecimento comum - o saber acerca do homem. Dos debates e consensos resultantes desta participação se consolidaram as proposições dos textos norteadores das políticas e, no escopo dessa participação, se observa a atuação desses grupos.

Destacamos, ainda, a masculinidade como uma construção histórico-social que, como tal, se expressa de maneira diferenciada ao longo do tempo, dos diferentes espaços culturais, das distintas etapas dos ciclos de vida do indivíduo, das relações de gêneros etc., o que nos sinaliza a necessidade de operar este conceito de forma mais ampliada, não reduzida a aspectos biopsíquicos ou circunscritas às etapas dos ciclos de vida, sob pena do encapsulamento dessas políticas que, em última instância, pretendem acolher o mesmo indivíduo ao longo de sua existência.

Frente a isso, nos aproximamos do conceito de cultura desenvolvido por Hall ${ }^{26}$, compreendido como um conjunto de sistemas ou códigos de significados que dão sentido às nossas ações, ou seja, as práticas sociais podem ser tomadas como práticas definidoras de um sistema regulatório dos modos de agir em sociedade. Um texto político expressa, portanto, uma política cultural nas quais se pode analisar tanto a resistência quanto os esforços para a instauração de certos sentidos, que resultam de processos de disputas pela hegemonia dos interesses dos diversos grupos sociais.

É interessante identificar as conquistas possibilitadas pelo reconhecimento dos direitos à saúde, que ganham contornos de textos políticos propositores de mudanças e rupturas. No entanto, outra possibilidade sinaliza uma questão - a de se pensar que adolescência, juventude e maturidade não são categorias abstratas, mas encarnadas em homens e mulheres. Nesse sentido, o gênero se constitui, portanto, numa categoria mais ampla e integradora, que provoca a reflexão sobre os dilemas dos ciclos de vida, seus limites, singularidades e conquistas.

\section{Colaboradores}

SB Lopez e MCN Moreira participaram igualmente de todas as etapas de elaboração do artigo. 


\section{Referências}

1. Brasil. Ministério da Saúde (MS). Datasus: Informações de Saúde. [acessado 2013 fev 27]. Disponível em: http://www.datasus.gov.br

2. Villela WV, Doreto DT. Sobre a experiência sexual dos jovens. Cad Saude Publica 2006; 22(11):24672472.

3. Mota MP da. Gênero e sexualidade: fragmentos de identidade masculina nos tempos da Aids. Cad Saude Publica 1998; 14(1):145-155.

4. Gomes R, Nascimento EF. A produção do conhecimento da saúde pública sobre a relação homemsaúde: uma revisão bibliográfica. Cad Saude Publica 2006; 22(5):901-911.

5. Brasil. Ministério da Saúde (MS). Secretaria de Atenção à Saúde. Departamento de Ações Programáticas Estratégicas. Área Técnica de Saúde do Adolescente e do Jovem. Diretrizes Nacionais para a Atenção Integral à Saúde de Adolescentes e Jovens na Promoção, Proteção e Recuperação da Saúde. Brasília: MS; 2010.

6. Brasil. Ministério da Saúde (MS). Secretaria de Atenção à Saúde. Departamento de Ações Programáticas Estratégicas. Política nacional de atenção integral à saúde do homem: princípios e diretrizes. Brasília: MS; 2009.

7. Connel RW. La organización social de la masculinidad 1997; 24:31-48. [acessado 2007 out 20]. Disponível em: http://www.cholonautas.edu.pe/biblioteca virtual de ciencias sociales.

8. Gomes R. Sexualidade Masculina, Gênero e Saúde. Rio de Janeiro: Editora Fiocruz; 2008.

9. Gomes R, Nascimento EF, Araújo FC. Por que os homens buscam menos os serviços de saúde do que as mulheres? As explicações de homens com baixa escolaridade e homens com ensino superior? Cad Saude Publica 2007; 23(3):565-574.

10. Brasil. Ministério da Saúde (MS). Secretaria de Atenção à Saúde. Departamento de Ações Programáticas Estratégicas. Área Técnica de Saúde do Adolescente e do Jovem. Política nacional de atenção integral à saúde de adolescentes e jovens (proposta preliminar). Brasília: MS; 2007.

11. Brasil. Portaria MS/GM no 1.944 de 27 de agosto de 2009. Institui no âmbito do Sistema Único de Saúde (SUS), a Política Nacional de Atenção Integral à Saúde do Homem. Diário Oficial da União 2009; 28 ago.

12. Severino AJ. Metodologia do Trabalho Científico. São Paulo: Cortez; 1993.

13. Minayo MCS. Hermenêutica-Dialética como Caminho do Pensamento Social. In: Minayo MCS, Deslandes SF, organizadores. Caminhos do pensamento. Epistemologia e método. Rio de Janeiro: Editora Fiocruz; 2002. p. 83-108.
14. Brasil. Constituição da República Federativa do Brasil de 1988. Diário Oficial da União 1988; out 5.

15. Brasil. Lei no 8069 de 13 de julho de 1990. Dispõe sobre o Estatuto da Criança e do Adolescente e dá outras providências. Diário Oficial da União 1990; jul 16.

16. Brasil Lei no 8.080 de 19 de setembro de 1990. Dispõe sobre as condições para a promoção, proteção e recuperação da saúde, a organização e o funcionamento dos serviços correspondentes e dá outras providências. Diário Oficial da União 1990; set 20.

17. Brasil. Lei 8.142 de 28 de dezembro de 1990. Dispõe sobre a participação da comunidade na gestão do Sistema Único de Saúde (SUS) e sobre as transferências intergovernamentais de recursos financeiros na área da saúde e dá outras providências. Diário Oficial da União 1990; dez 31.

18. Arantes EMM. De "criança infeliz" a "menos irregular" - Vicissitudes na arte de governar a infância. [acessado 2010 mar 05]. Disponível em: http://www. cliopsyche.uerj.br/livros/clio1/decriancainfeliz.htm

19. Pires SFS. Cultura, self e autonomia: bases para o protagonismo infantil. Psicologia: teoria e pesquisa 2008; 24(4):415-421.

20. Pires SFS, Branco AU. Protagonismo infantil: coconstruindo significados em meios às práticas sociais. Paidéia 2007; 17(38):311-320.

21. Brasil. Ministério da Saúde (MS). Discurso de Posse do Ministro José Temporão de 19 de março de 2007. Brasília: MS; 2007.

22. Costa JF. Ordem Médica e norma familiar. Rio de Janeiro: Edições Graal; 1999.

23. Rohden F. A arte de enganar a natureza. Rio de Janeiro: Editora Fiocruz; 2003.

24. Farias CAP. Idéias, conhecimento e políticas públicas - um inventário sucinto das principais vertentes analíticas recentes. Revista Brasileira das Ciências Sociais 2003; 18(51):21-29.

25. Carvalheiro JR. Os desafios para a saúde. Estudos Avançados 1999; 13(35):7-20.

26. Hall S. A centralidade da cultura: notas sobre as revoluções culturais do nosso tempo. [acessado 2005 ago 22]: Disponível em: http://www.educacao online.pro.br/index.php?option $=$ com_content $\&$ view $=$ article $\& \mathrm{id}=117$ : $\mathrm{a}$-centralidade-da-culturanotas-sobre-as-revolucoes-culturais-do-nossotempo\&catid $=8:$ multiculturalismo\&Itemid $=19$.

Artigo apresentado em 10/07/2011

Aprovado em 15/08/2011

Versão final apresentada em 15/09/2011 